NASA Technical Memorandum 107314

AIAA-96-4163

\title{
A General-Purpose Optimization Engine for Multi-Disciplinary Design Applications
}

Surya N. Patnaik

Ohio Aerospace Institute

Cleveland, Ohio

Dale A. Hopkins and Laszlo Berke

Lewis Research Center

Cleveland, Ohio

Prepared for the

Sixth Multidisciplinary Analysis and Optimization Symposium

cosponsored by AIAA, NASA, and USAF

Bellevue, Washington, September 4-6, 1996

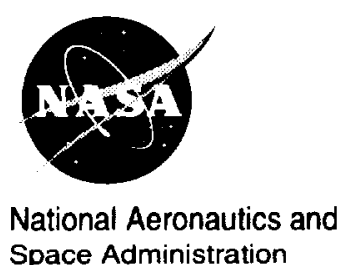

Space Administration 


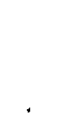




\title{
GENERAL-PURPOSE OPTIMIZATION ENGINE FOR MULTIDISCIPLINARY DESIGN APPLICATIONS
}

\author{
Surya N. Patnaik, ${ }^{*}$ Dale A. Hopkins, and Lazlo Berke \\ National Aeronautics and Space Administration \\ Lewis Research Center \\ Cleveland, Ohio 44135
}

\begin{abstract}
$\underline{\text { Abstract }}$
A general purpose optimization tool for multidisciplinary applications, which in the literature is known as COMETBOARDS, is being developed at NASA Lewis Research Center. The modular organization of COMETBOARDS includes several analyzers and state-of-the-art optimization algorithms along with their cascading strategy. The code structure allows quick integration of new analyzers and optimizers. The COMETBOARDS code reads input information from a number of data files, formulates a design as a set of multidisciplinary nonlinear programming problems, and then solves the resulting problems. COMETBOARDS can be used to solve a large problem which can be defined through multiple disciplines, each of which can be further broken down into several subproblems. Alternatively, a small portion of a large problem can be optimized in an effort to improve an existing system. Some of the other unique features of COMETBOARDS include design variable formulation, constraint formulation, subproblem coupling strategy, global scaling technique, analysis approximation, use of either sequential or parallel computational modes, and so forth. The special features and unique strengths of COMETBOARDS assist convergence and reduce the amount of CPU time used to solve the difficult optimization problems of aerospace industries. COMETBOARDS has been successfully used to solve a number of problems, including structural design of space station components, design of nozzle components of an air-breathing engine, configuration design of subsonic and supersonic aircraft, mixed flow turbofan engines, wave rotor topped engines, and so forth. This paper introduces the COMETBOARDS design tool and its versatility, which is illustrated by citing examples from structures, aircraft design, and air-breathing propulsion engine design.
\end{abstract}

Introduction

A multidisciplinary optimization engine, which in the literature is known as COMETBOARDS, is being developed at NASA Lewis Research Center for the design of structural components, subsonic and supersonic aircraft configuration design, and airbreathing propulsion engine design. The COMETBOARDS design tool has provision to accommodate up to ten different disciplines; each of these can have a maximum of five subproblems. The design tool in other words can optimize a system which can be defined in terms of fifty optimization subproblems. Each subproblem can be defined with its own design variables, constraints, and an objective function. Computation at the subproblem level can be carried out either in sequential or in parallel computational modes. Interdisciplinary coupling, an important strategy for successful solution of the problem, is accomplished through coupling at the design variable level and through local and global constraint formulations. On the other hand, by appropriate data specification, COMETBOARDS can also be used to examine the optimality of a small portion of a much larger design problem.

The COMETBOARDS system first formulates the design as a nonlinear mathematical programming problem, reading data from specified input files, and then solves the resulting problem. Problem formulation can utilize a number of analysis tools available in its 'Analyzers' module. Representative analysis tools currently available in COMETBOARDS include, RPK/NASTRAN ${ }^{l}$ for structural analysis, NASA Engine Performance Program (NEPP) ${ }^{2}$ for air-breathing engine performance analysis, and Flight Optimization Systems (FLOPS) ${ }^{3}$ for aircraft performance analysis. The code allows soft-coupling and quick integration of new analyzers. COMETBOARDS solution

*Ohio Aerospace Institute, Cleveland, Ohio

"This paper is declared a work of the U.S. Government

and is not subject to copyright protection in the United States." 
technique exploits several of its unique strengths, which are available in its 'Optimizers' module. COMETBOARDS is written in Fortran 77 language and tested in Cray and Convex computers and in SGI and Sun Unix workstations. Successful COMETBOARDS solutions for a number of diverse industrial problems, from different disciplines corroborate the robustness and versatility of the design tool. With augmentation and improvement, the research level optimization capability of COMETBOARDS has the potential of becoming a robust design tool for the aerospace industry.

This paper includes an overview of the design tool COMETBOARDS. Three applications (one each, from structures, aircraft design, and airbreathing propulsion engine concepts) are given to illustrate the versatility and robustness of COMETBOARDS.

\section{COMETBOARDS Design Tool}

The modular organization of COMETBOARDS is depicted in Fig. 1. The key features of COMETBOARDS include its multidisciplinary nature (with a separate objective, constraints, and variables for each discipline, which can be further broken down into several subproblems), substructure optimization (with coupling strategy available in sequential as well as in parallel computational modes), state-of-the-art optimization algorithms and their cascading 4 strategies, and analysis approximations by means of linear regression analysis and neural network. The COMETBOARDS modular organization is like a test bed, and a user has considerable flexibility such as (1) solving a problem by using available analyzers and optimizers in the code, (2) adding analyzers through softcoupling into COMETBOARDS and then solving problems, (3) checking out the performance of new analyzers, (4) checking out the performance of a new optimizer utilizing the 40 or so problems available in the COMETBOARDS solved-examplestest-bed; just to mention a few. Space does not permit the description of the other features and unique strengths of the design tool COMETBOARDS, some aspects of which can be found in Refs. [5, 6, and 7]. Only the cascade strategy required to optimize aircraft and engine problems is described next.

\section{Cascade Optimization Strategy}

COMETBOARDS provides for the solution of difficult optimization problems by means of a cascade strategy. The basic cascade concept is an attempt to solve a complex problem by using more than one optimizer, when individual optimizers face difficulties. The cascade concept and its flow diagram are depicted in Fig. 2. A COMETBOARDS user has considerable flexibility in developing a cascade strategy, by selecting a number of optimizers (currently about one dozen different nonlinear programming algorithms are available), their convergence criteria, analysis approximations, and the amount of random perturbations between optimizers. Consider for the purpose of illustration, the cascade concept, first optimizer, followed by several other optimizers, shown in Fig. 2(a). Individual convergence criteria can be specified for each optimizer; for example, a coarse stop criteria may be sufficient for the first optimizer, while a fine stop criteria can be stipulated for the last optimizer. Likewise approximate analysis may suffice for the first optimizer, reserving an accurate analyzer for the final optimizer. The amount of pseudo random perturbations for design variables between the optimizers may be specified at the discretion of the user.

\section{Substructure Optimization Strategy}

Design optimization of large structural systems can be attempted by using the substructuring strategy available in COMETBOARDS. In this strategy the original structure is divided into several smaller substructures. The design of the entire structure can be accomplished by repeated optimizations of the substructures. Substructure optimization can use either sequential or parallel computational platforms.

The substructure optimization strategy available in COMETBOARDS is illustrated by considering the example of the support system of the long spacer structure of the International Space Station as shown in Fig. 3. The support system, which for analysis is idealized by shell elements, is divided into four segments and four substructures as depicted in Fig. 3. Substructure (1) includes all shell elements within segments 3 and 4 , substructure (2) includes all shell elements within segments 4 and 1 , substructure (3) includes all shell elements within segments 1 and 2, and substructure (4) includes all shell elements within segments 2 and 3 . The substructuring process incorporates adequate design variable coupling, which is essential for the success of the strategy. Notice, for example, the coupling between the first and fourth substructures through the elements in segment 4 , which are common to both.

The thickness of all shell elements within a segment were grouped to obtain a single active design variable. Thus, each substructure has two active design variables; namely, substructure (1) contains the third and fourth design variables, substructure (2) contains the fourth and the first design variables, and so forth.

The behavior constraints were separated into local and global sets. Separation of behavior 
constraints into local and global sets is essential for convergence of the substructure strategy 8 . The first set included the local stress constraints associated with each substructure; these were reduced by following the constraints formulation scheme available in the design tool COMETBOARDS. The other set included global displacement constraints which were considered common for all substructures.

The final optimum results for the support system were obtained after three complete design cycles, which totaled solutions of 12 optimization subproblems. The substructure design sequence is depicted in Fig. 4. Notice, for example, the reduction in the weight of substructure (1) in Fig. 4, between cycles 1 and 2 , and between cycles 2 and 3 . In first two cycles there is a considerable reduction in the weight, while convergence occurred during the next two cycles. Other subproblem characteristics follow the pattern with some deviations.

Optimum results for the problem are shown in Table I. The optimum weight for the support system obtained by using the substructure technique is $34.71 \mathrm{lb}$; there are three active constraints. The optimum result is in good agreement with the optimum solution of $34.68 \mathrm{lb}$ which was obtained when the entire structure was designed as a single unit. Likewise the values of the design variables at the optimum, shown in Table I, agreed when substructuring and single-step optimization were used. Both techniques produced the same three active constraints.

\section{Design Optimization of Supersonic Aircraft Concept}

Design optimization of both subsonic and supersonic aircraft concepts has been attempted successfully through a soft-coupling of the Flight Optimi-zation Systems (FLOPS) as the analyzer and COMETBOARDS as the optimizer. The FLOPS analyzer through input data specifications can be used to analyze both subsonic and supersonic aircraft. The FLOPS analyzer uses several different disciplines to predict aircraft performance. The different disciplines available in a modular form include weight, aerodynamics, engine cycle analysis, propulsion data interpolation, mission performance, takeoff and landing, noise footprint, and cost. The combined design tool with FLOPS as the analyzer and COMETBOARDS as the optimizer has been successfully used to solve a number of subsonic and supersonic aircraft problems. The example of a supersonic aircraft is given here to illustrate COMETBOARDS capability.

The takeoff gross weight is considered as the merit function of the aircraft problem. Six independent design variables are considered; they are (1) engine thrust (in lb), (2) wing size (in sq ft),
(3) engine turbine inlet temperature (in ${ }^{\circ} \mathrm{R}$ ), (4) engine overall pressure ratio, (5) bypass ratio, and (6) fan pressure ratio. The six critical behavior constraints included are (1) landing approach velocity, (2) takeoff field length, (3) missed approach, (4) second segment climb, (5) jet velocity, and (6) compressor discharge temperature.

The resulting multidisciplinary optimization problem has distorted design space since both design variables and constraints varied over a very wide range. For example an engine thrust design variable (which is measured in kip) is immensely different from the bypass ratio variable (which is a small number). Likewise, landing velocity constraint (in knots) and field length limitation (in thousands of $\mathrm{ft}$ ) differ both in magnitude and in units of measure. The difficult nature of the design problem is further compounded because of the statistical and empirical equations, the smoothing techniques, and so forth, employed in the FLOPS analyzer. In other words, the FLOPS analyzer can be numerically unstable for some combinations of design variables, especially for a supersonic aircraft. The unique features of COMETBOARDS, especially the scaling and the cascade strategy, assisted the convergence of the difficult problem.

To examine the robustness of the COMETBOARDS-FLOPS combined design tool, six different aircraft design test cases with different starting points and variable bounds were devised at NASA Langley Research Center. Only five cases will be given in this paper. All the test problems have been solved by using NASA Lewis' COMETBOARDS. Optimum solutions for all five cases are given in Table II. This table reveals the following:

(1) Both COMETBOARDS and another optimizer successfully solved all five test cases.

(2) Optimum solutions obtained by both COMETBOARDS and other optimizers were comparable. The average COMETBOARDS optimum solution at $666,550.0 \mathrm{lb}$ was about 1 percent lighter than the other optimizers results at $673,273.0 \mathrm{lb}$.

(3) Optimum values for the design variables obtained using COMETBOARDS and other optimizers codes compared well with minor differences. Likewise constraint values agreed well between the two design tools, except for the second segment climb thrust (SSFOR). When COMETBOARDS was used, SSFOR was at $21.72 \mathrm{lb}$, while the other optimizer resulted in a value of $607 \mathrm{lb}$

The optimum solution obtained has been verified graphically in Fig. 5. The optimum lies at the intersection of three active constraints, namely, compressor discharge temperature, jet velocity, and second segment climb thrust. With respect to design 
variables, bypass ratio, and fan pressure ratio, the unconstrained minimum condition is achieved without any active constraint.

\section{Design of a Mixed flow Turbofan Engine for High- Speed Civil Transport System}

Design optimization of air-breathing engines for high-speed civil transport applications has been developed through a soft-coupling of the NASA Engine Performance Program (NEPP) with the optimization tool COMETBOARDS. The combined COMETBOARDS-NEPP computer simulation is an attempt to optimize the design of multimission variable cycle engines with specified hardware components and configurations with designated interconnections. The solution to the nonlinear engine design problem when attempted through any one of the dozen robust optimizers available in COMETBOARDS could provide a feasible optimum solution for only a portion of the aircraft flight regime because of a large number of mission points (defined through altitudes, Mach numbers, and power setting combinations) with diverse constraints (specified on pressure ratios, temperatures, speed corrections, mass flow rates, etc.) and over all ill-conditioned design space. Utilization of the unique strengths of COMETBOARDS (such as the cascade strategy, global scaling technique, design variables, and constraint formulations) successfully solved a number of difficult engine design optimization problems.

The COMETBOARDS solution for a 122mission-point turbofan engine is given here as the last numerical example. The 122 mission points for the mixed flow turbofan (MFTF) engine is depicted in Fig. 6. The design optimization of the MFTF engine required the solution of a sequence of 122 optimization subproblems, one for each mission point. For each mission point, the thrust of the engine was considered as the merit function. The following important active design variables were considered: pressure balance in the mixer, R-values for fans and compressors, fan speed, and so forth. The important constraints considered were the following: the maximum speed of the compressor, acceptable surge margin for the compressor, the discharge temperatures, the mixer entrance Mach number, and so forth. The most reliable individual optimization algorithm available in COMETBOARDS could provide feasible results for only a portion of the 122mission-point flight envelope because of the sequence of a large number of optimization subproblems, diverse constraint types, and overall illconditioning of the design space. A four optimizer cascade strategy could successfully solve the engine design problem for the entire 122-mission-point flight envelope. Furthermore, the cascade strategy converged to the same global solution when begun from different design points. The cascade solution was normalized with respect to the NEPP results, which were obtained by using an individual optimizer and manual interventions. The normalized solution, which is shown in Fig. 7, was found to be superior for most of the 122 mission points, except for a few cases for which both (COMETBOARDS and NEPP) optimum results agreed. For flights around mission point 70, COMETBOARDS results for optimum thrust were about 10 percent higher than the NEPP solution. In brief, the cascade optimization strategy successfully solved the 122- mission-point mixed-flow turbofan engine design problem.

\section{Conclusions}

COMETBOARDS, with its unique strengths and strategies, has been used successfully to solve a number of problems from structures, aircraft, and air-breathing propulsion engines. Successful COMETBOARDS solutions for three difficult examples (i.e., (1) design optimization of a support system solved by using substructuring capability, (2) supersonic aircraft configuration optimization, and (3) mixed flow turbofan thrust optimization) illustrate the versatility of the code. The cascade strategy of COMETBOARDS was required to generate solutions for the aircraft and engine problems. COMETBOARDS, which is written in Fortran 77 language with parallel computational facility, is available in the Cray-YMP and Unix workstations. With some enhancements and modifications, the research level COMETBOARDS, which has been found robust and reliable for multidisciplinary design applications has the potential of becoming a useful design tool for aerospace industry.

\section{$\underline{\text { References }}$}

1. RPK/NASTRAN, COSMIC, University of Georgia, Athens, GA.

2. Klann, J.N.; and Snyder, C.A.: NEPP Programmers Manual. NASA TM-106575, 1994.

3. McCullers, L.A.: FLOPS: Aircraft Configuration Optimization Including Optimized Flight Profiles. NASA CP-2327, 1984.

4. Patnaik, S. N.; Coroneos R. M.; and Hopkins, D.A.: A Cascade Optimization Strategy for Solution of Difficult Multidisciplinary Design Problems. AIAA/ASME/ASCE/AHS/ASC 37th Structures, Structural Dynamics, and Materials Conference, April 15-17, 1996, Salt Lake City, UT. 
5. Guptill, J.D.; et al.: COMETBOARDS User's Manual, NASA TM-4537, 1996.

6. Patnaik, S.N.; et al.: Comparative Evaluation of Different Optimization Algorithms for Structural Design Applications. Int. Jnl. Num. Meth. Of Engr., Vol. 39, pp. 1761-1774, 1996.

7. Patnaik, S.N.; Gendy, A.S.; and Hopkins D.A.: Design Optimization of Large Structural Systems
With Substructuring in a Parallel Computational Environment. Computer Systems in Engineering. Vol. 5, No.4-6, pp. 425-440, 1994.

8. Gendy, A..S.; et al.: Issues in Substructure Optimization.WCSMO-1, Structural and Multidisciplinary Optimization, pp. 857-862, 1995.

Table I.-Optimum Design Of Support System

(a) Weight

\begin{tabular}{|c|c|c|}
\hline Design cycle number & \multicolumn{2}{|c|}{$\begin{array}{c}\text { Weight, } \\
\text { lb }\end{array}$} \\
\cline { 2 - 3 } & Substructuring & No substructuring \\
\hline 0 (initial) & 54.35 & 54.35 \\
\hline 1 & 34.04 & 34.68 (optimum) \\
\hline 2 & 34.74 & \\
\hline 3 (optimum) & 34.71 & \\
\hline
\end{tabular}

(b) Design variables

\begin{tabular}{|c|c|c|c|}
\hline \multirow{2}{*}{ Substructure } & $\begin{array}{c}\text { Design variables, } \\
\text { in. }\end{array}$ & \multicolumn{2}{|c|}{ Optimum design } \\
\cline { 2 - 4 } & Initial & Substructuring & No substructuring \\
\hline I & 0.2 & 0.1277 & 0.1277 \\
\hline II & 0.2 & 0.1298 & 0.1295 \\
\hline III & 0.2 & 0.1765 & 0.1766 \\
\hline IV & 0.2 & 0.0264 & 0.0263 \\
\hline
\end{tabular}

Table II.-Optimum Design for Five NASA Langley Research Center Supersonic Aircraft Test Cases

\begin{tabular}{|c|c|c|}
\hline \multirow{2}{*}{ Test cases } & \multicolumn{2}{|c|}{$\begin{array}{c}\text { Takeoff gross weight } \\
\text { (normalized) }\end{array}$} \\
\cline { 2 - 3 } & COMETBOARDS & Other optimizers \\
\hline 1 & 0.99997 & 1.01785 \\
\hline 2 & 1.00004 & 1.00184 \\
\hline 3 & 1.00005 & 1.02855 \\
\hline 4 & 0.99996 & 1.00200 \\
\hline 5 & 0.99997 & 1.00019 \\
\hline Average & $\mathbf{1 . 0}(\mathbf{6 6 6 , 5 5 0 . 0} \mathbf{l b})$ & $\mathbf{1 . 0 0 0 1 9}(\mathbf{6 7 3 2 7 3 . 0} \mathbf{l b})$ \\
\hline
\end{tabular}




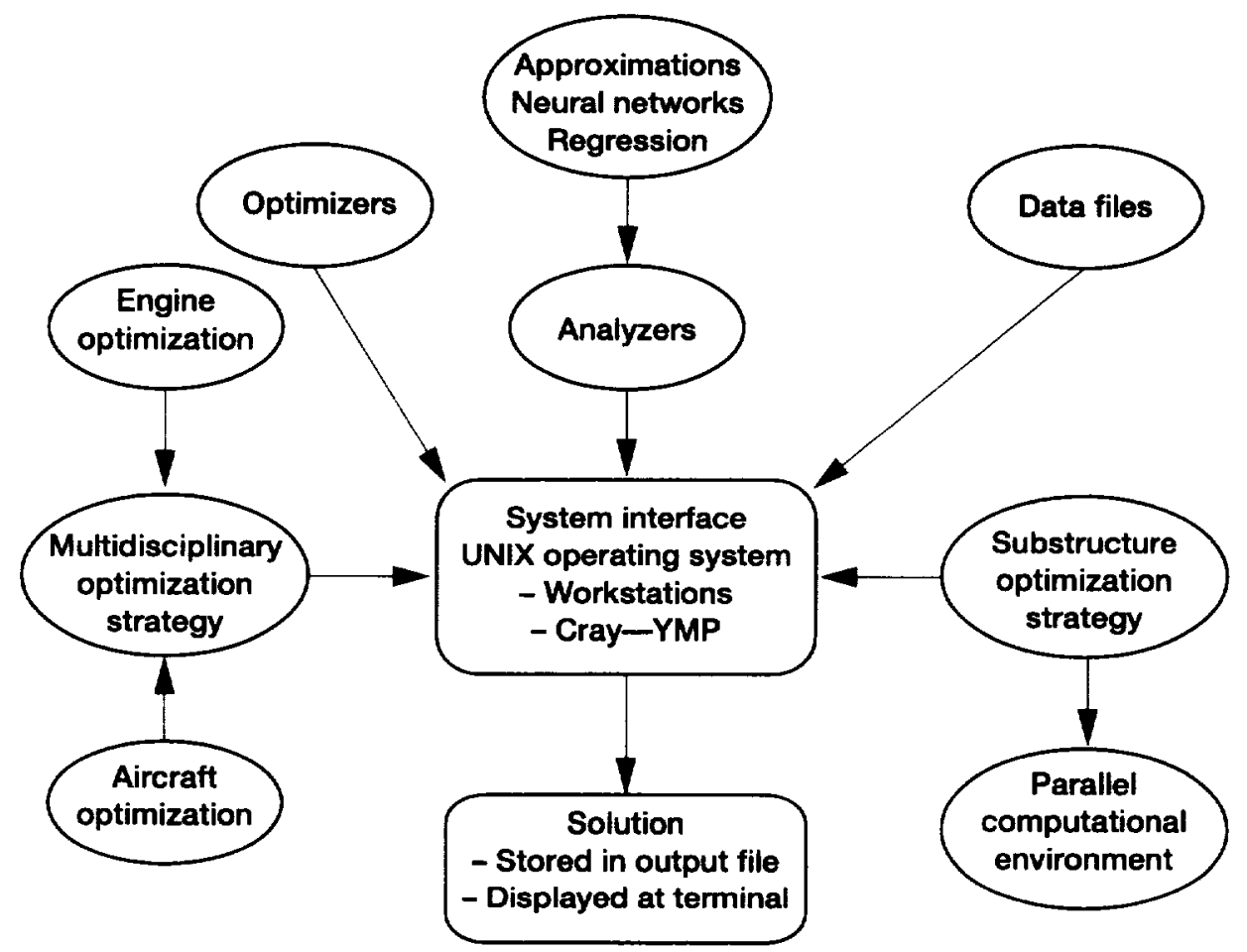

Fig. 1.- Organization of COMETBOARDS design tool.

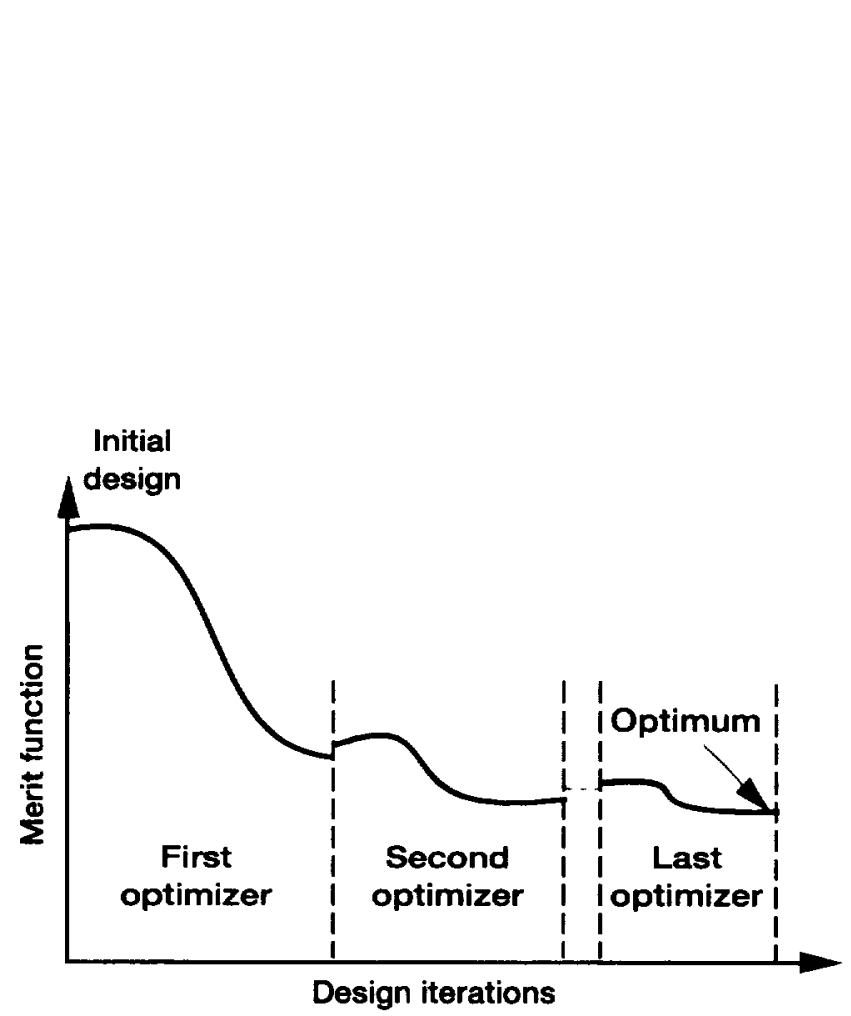

(a)

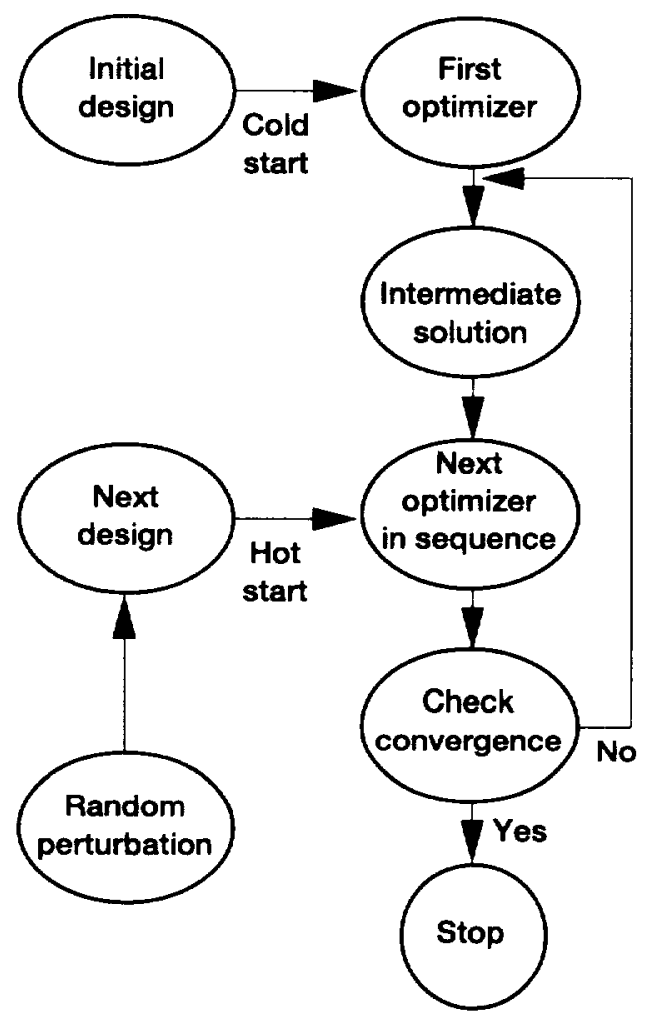

(b)

Fig. 2.-Cascade strategy in COMETBOARDS. (a) Cascade concept. (b) Flow diagram. 


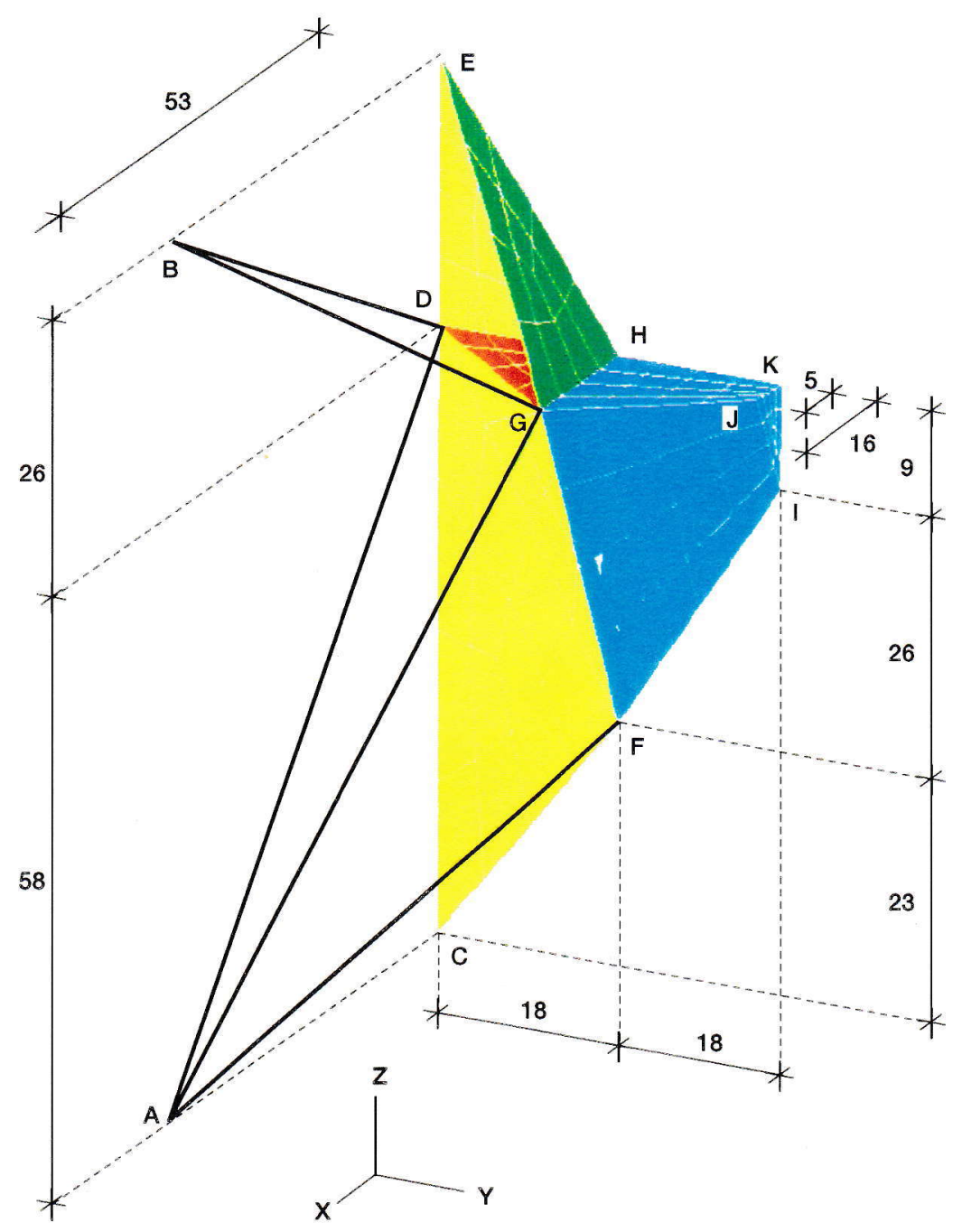

Fig. 3.-Support of long spacer structure of International Space Station.

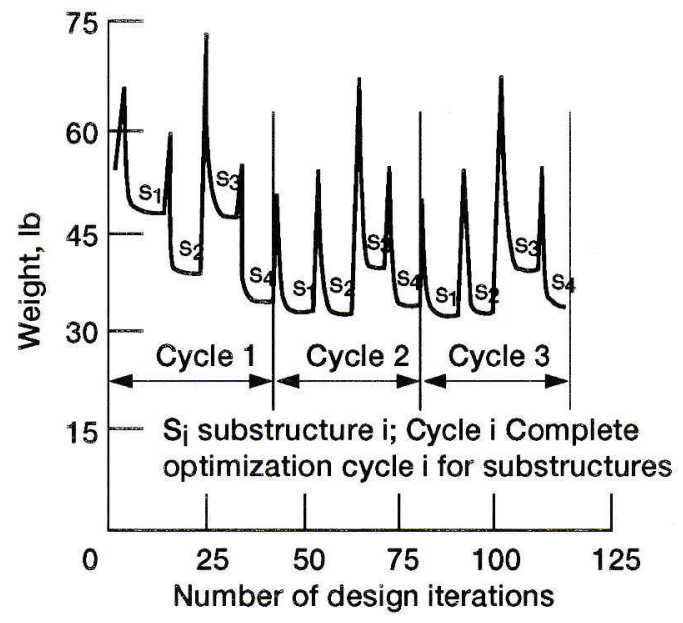

Fig. 4.-Convergence characteristics of substructure optimization of support system. 


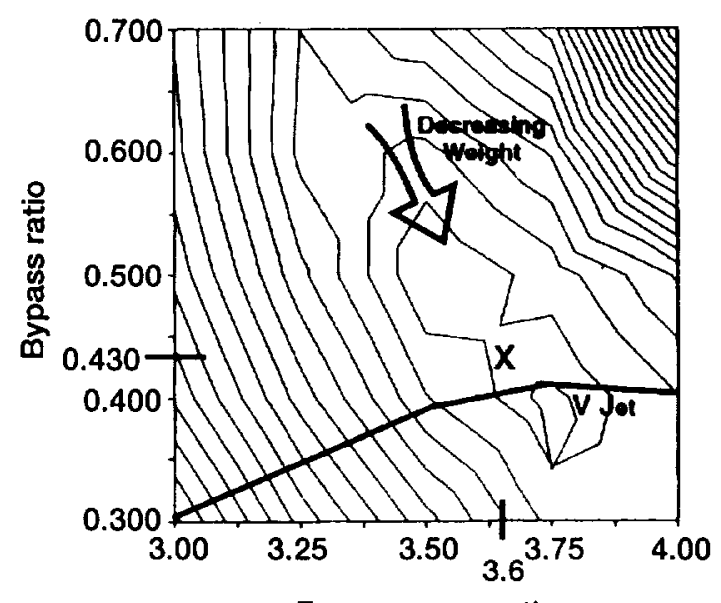

Fan pressure ratio

(a)

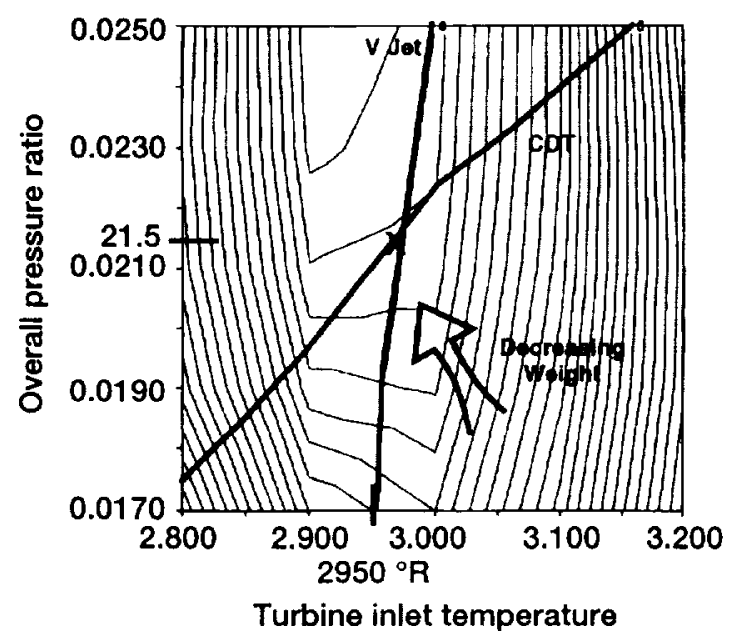

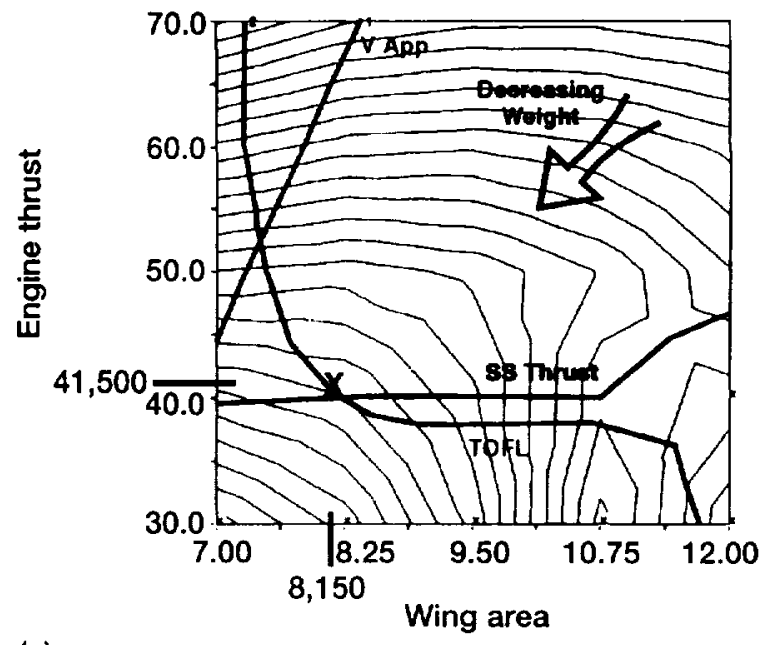

(c)

(b)

Fig. 5.-Graphical verification of optimum design of supersonic aircraft. (a) Fan pressure ratio. (b) Turbine inlet temperature. (c) Wing area. 


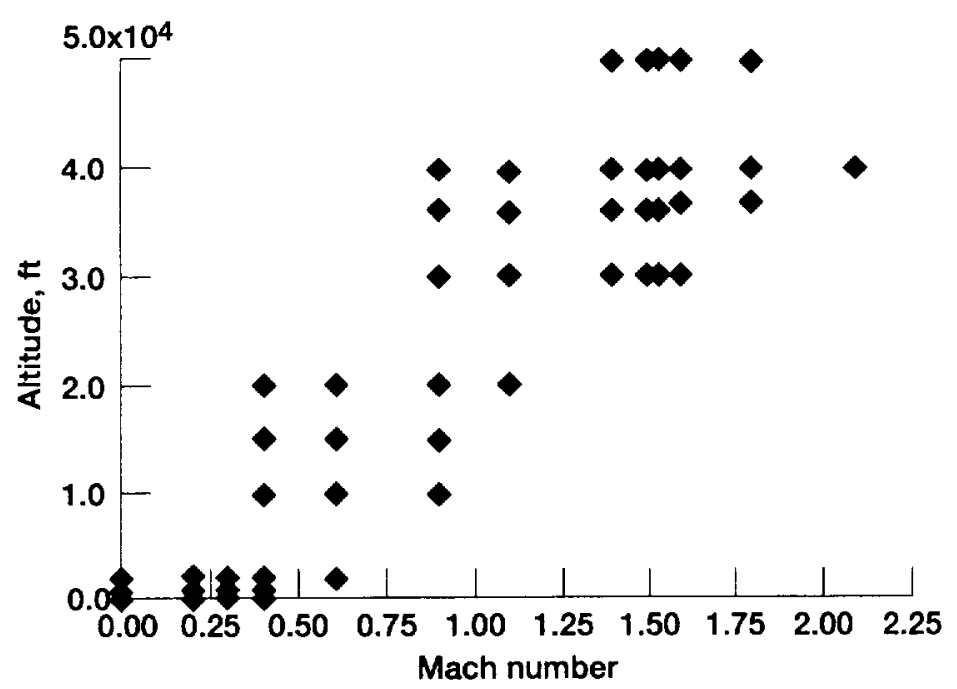

Fig. 6. -Flight envelope for High-Speed Civil Transport mixed flow turbofan engine.

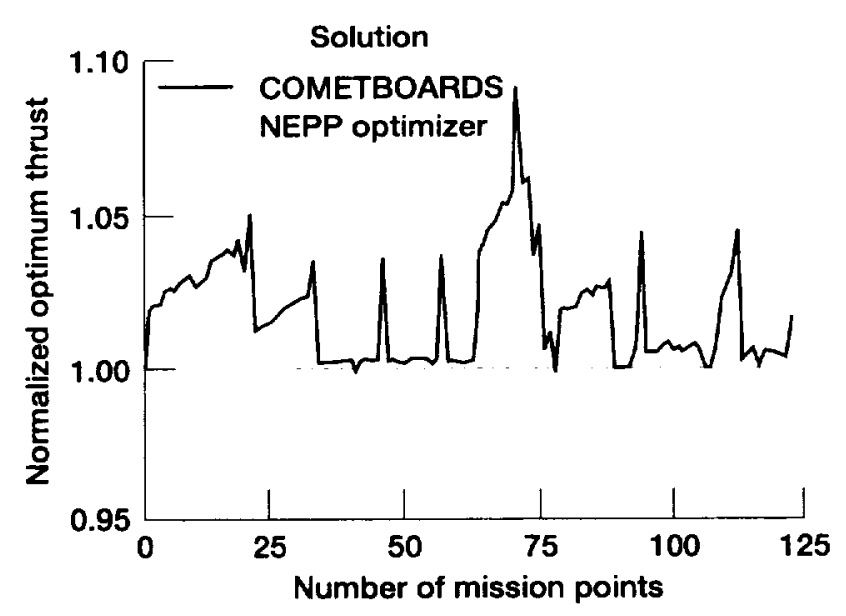

Fig. 7.-122 mission points for mixed flow turbofan (MFT) engine. 

Public reporting burden for this collection of information is estimated to average 1 hour per response, including the time for reviewing instructions, searching existing data sources, gathering and maintaining the data needed, and completing and reviewing the collection of information. Send comments regarding this burden estimate or any ofher aspect of this Davis Highway, Suite 1204, Artington, VA 22202-4302, and to the Otfice of Management and Budget, Paperwork Reduction Project (0704-0188), Washington, DC 20503.

\begin{tabular}{|l|c|c|}
\hline 1. AGENCY USE ONLY (Leave blank) & $\begin{array}{c}\text { 2. REPORT DATE } \\
\text { August } 1996\end{array}$ & $\begin{array}{r}\text { 3. REPORT TYPE AND DATES COVERED } \\
\text { Technical Memorandum }\end{array}$ \\
\hline
\end{tabular}

\section{TITLE AND SUBTITLE}

5. FUNDING NUMBERS

A General-Purpose Optimization Engine for Multi-Disciplinary

Design Applications

6. AUTHOR(S)

WU-505-63-5B

Surya N. Patnaik, Dale A. Hopkins, Laszlo Berke

\section{PERFORMING ORGANIZATION NAME(S) AND ADDRESS(ES)}

National Aeronautics and Space Administration

Lewis Research Center

Cleveland, Ohio 44135-3191
8. PERFORMING ORGANIZATION REPORT NUMBER

E-10409
9. SPONSORINGMONITORING AGENCY NAME(S) AND ADDRESS(ES)

National Aeronautics and Space Administration

Washington, D.C. 20546-0001
10. SPONSORINGMONITORING AGENCY REPORT NUMBER

NASA TM- 107314

AIAA-96-4163

11. SUPPLEMENTARY NOTES

Prepared for the Sixth Multidisciplinary Analysis and Optimization Symposium cosponsored by AIAA, NASA, and USAF, Bellevue, Washington, September 4-6, 1996. Surya N. Patnaik, Ohio Aerospace Institute, 22800 Cedar Point Road, Cleveland, Ohio 44142; Dale A. Hopkins and Laszlo Berke, NASA Lewis Research Center. Responsible person, Dale A. Hopkins, organization code 5210, (216) 433-3260.

12a. DISTRIBUTION/AVAILABILITY STATEMENT

12b. DISTRIBUTION CODE

Unclassified - Unlimited

Subject Category 39

This publication is available from the NASA Center for AeroSpace Information, (301) 621-0390.

13. ABSTRACT (Maximum 200 words)

A general purpose optimization tool for multidisciplinary applications, which in the literature is known as COMETBOARDS, is being developed at NASA Lewis Research Center. The modular organization of COMETBOARDS includes several analyzers and state-of-the-art optimization algorithms along with their cascading strategy. The code structure allows quick integration of new analyzers and optimizers. The COMETBOARDS code reads input information from a number of data files, formulates a design as a set of multidisciplinary nonlinear programming problems, and then solves the resulting problems. COMETBOARDS can be used to solve a large problem which can be defined through multiple disciplines, each of which can be further broken down into several subproblems. Alternatively, a small portion of a large problem can be optimized in an effort to improve an existing system. Some of the other unique features of COMETBOARDS include design variable formulation, constraint formulation, subproblem coupling strategy, global scaling technique, analysis approximation, use of either sequential or parallel computational modes, and so forth. The special features and unique strengths of COMETBOARDS assist convergence and reduce the amount of CPU time used to solve the difficult optimization problems of aerospace industries. COMETBOARDS has been successfully used to solve a number of problems, including structural design of space station components, design of nozzle components of an air-breathing engine, configuration design of subsonic and supersonic aircraft, mixed flow turbofan engines, wave rotor topped engines, and so forth. This paper introduces the COMETBOARDS design tool and its versatility, which is illustrated by citing examples from structures, aircraft design, and air-breathing propulsion engine design.

14. SUBJECT TERMS

Multi-disciplinary optimization; Nonlinear programming algorithms and cascade substructure; Parallel computation

\begin{tabular}{l|c|}
\hline 17. SECURTYY CLASSIFICATION & $\begin{array}{c}\text { 18. SECURTYY CLASSIFICATION } \\
\text { OF REPORT } \\
\text { OF THIS PAGE } \\
\text { Unclassified }\end{array}$
\end{tabular}

\section{SECURITY CLASSIFICATION} OF ABSTRACT Unclassified 


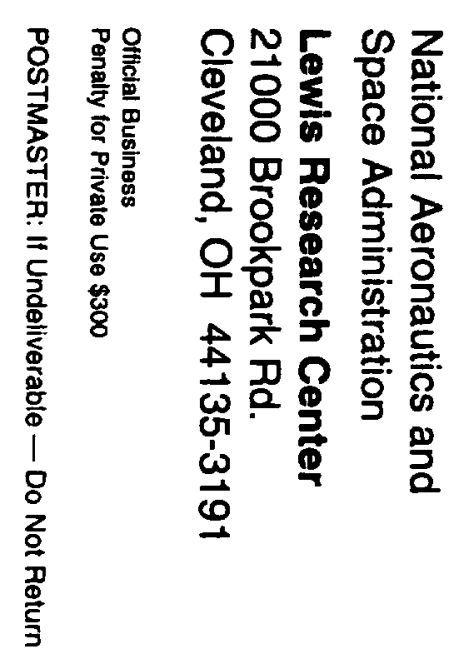

